\title{
Operations Research and Organizational Decision-Making in Academic Libraries
}

Therrin C. Dahlin

terry_dahlin@byu.edu

Follow this and additional works at: https://scholarsarchive.byu.edu/facpub

Part of the Library and Information Science Commons, and the Organizational Communication

Commons

\section{Original Publication Citation}

Dahlin, T. C."Operations Research and Organizational Decision-Making in Academic Libraries."

Collection Management 14.3/4 (1991): 49-6.

\section{BYU ScholarsArchive Citation}

Dahlin, Therrin C., "Operations Research and Organizational Decision-Making in Academic Libraries" (1991). Faculty Publications. 1184.

https://scholarsarchive.byu.edu/facpub/1184

This Peer-Reviewed Article is brought to you for free and open access by BYU ScholarsArchive. It has been accepted for inclusion in Faculty Publications by an authorized administrator of BYU ScholarsArchive. For more information, please contact ellen_amatangelo@byu.edu. 


\title{
Operations Research \\ and Organizational Decision-Making in Academic Libraries
}

\author{
Therrin C. Dahlin
}

\begin{abstract}
Operations research entered the library scene in the 1960s and '70s, and has attracted much interest from librarians. This paper examines the assumptions made by selected operations researchers concerning organizational decision-making in academic libraries. The assumptions then are compared to Richard L. Daft's contingency framework of organizational decision-making to determine the appropriateness of applying operations research assumptions and methods to organizational decision-making in an academic library setting.

A review of the operations researchers' assumptions and Daft's framework suggests that the operations research approach may be appropriately applied to only a relatively narrow category of problems in academic libraries that match the stated assumptions. There are many other important academic library problems that are not well adapted to the operations researchers' craft.
\end{abstract}

Martha Boaz, former dean of the library school at the University of Southern California, bluntly characterizes the state of library research: "As compared with most well-established disciplines, the library profession has done little actual research." She asserts that library research tends to be narrow and provincial, and is comprised more of local studies than of rigorous, structured research. ${ }^{2}$

McClure and Samuels apply a similarly dismal assessment to the litera-

Therrin C. Dahlin is Head, Documents and Maps, at the Harold B. Lee Library, 1354 HBLL, Brigham Young University, Provo, UT 84602. The author received an MLS in 1974 from Brigham Young University, and is a PhD candidate, Higher Education, at the University of Utah.

Collection Management, Vol. 14(3/4) 1991

(C) 1991 by The Haworth Press, Inc. All rights reserved. 
ture of library administration. They observe that the field of library administration has not integrated modern management theories with library practices. Some writers use extremely practical approaches without giving thought to underlying theory, while others treat library administration as nothing more than a variation of business administration. ${ }^{3}$

There is one movement, however, that entered the library scene in the
thing more than a variation of business administration. 1960 s and '70s that carries with it the possibility of improving library research. Operations research (OR) techniques that proved so successful in military and industrial settings during and after World War II are being applied to library problems. Mackenzie and Buckland noted as early as 1969 that they had compiled a list of 280 papers on OR in libraries. ${ }^{4}$ Operations researchers have studied the optimum size of library collections, circulation loan periods, and the organization of book stacks, among other themes.

OR generates a fair amount of interest because it appears to be a legitimate scientific approach to the study of academic libraries. OR possesses the potential for answering some of the criticisms of library research and for increasing the status and prestige of the library profession.

However, any scholarly movement that enjoys rapid acceptance must be viewed with a degree of caution. The prospect of enhanced status and prestige may hinder critical examination of the assumptions and methods of the movement. OR may represent a significant step forward for library research and for the library profession. But OR studies make important assumptions about the nature of academic libraries. These assumptions should be analyzed carefully to ensure that techniques developed for other organizational settings may be profitably applied to academic libraries.

OR is often seen as part of the administrative process, particularly as an adjunct to organizational decision-making. Specific questions suggest themselves as $\mathrm{OR}$ and organizational decision-making are considered in relation to academic libraries.

1. What assumptions do operations researchers make about organizational decision-making and academic libraries?

2. Are operations researchers' assumptions about organizational decision-making and academic libraries accurate?

3. Are OR techniques, largely adapted from industry and government, being properly applied in the academic library setting?

The purpose of this paper is to examine the assumptions of operations researchers concerning organizational decision-making in academic libraries. Such assumptions appearing in selected OR writings will be outlined and discussed. Then the assumptions will be analyzed according to a 
contingency framework of organizational decision-making to shed light on the appropriateness of applying OR assumptions and methods to decision-making in academic libraries.

Two key terms require clarification. Organizational decision-making is defined as the process of identifying and solving problems. Operations research is defined as the application of scientific, often mathematical, methods to the study of complex systems. Morse explains that OR uses various techniques adapted from the physical sciences and engineering.' Mackenzie and Buckland (1976) elaborate on the methods used in OR:

OR is based on applying a scientific approach to practical problems; it normally operates in four distinct stages:

1. Description of the system being considered, especially by means of mathematical models and computer simulations;

2. Measurement, using objective data whenever these can be obtained;

3. Evaluation; the presentation of relevant information to the system manager (here, the librarian) to aid him in making decisions between different courses of action;

4. Operational control, assisting in the development of ways and means of achieving the objectives aimed for over a period of time.

\section{ASSUMPTIONS}

\section{ABOUT ORGANIZATIONAL DECISION-MAKING}

Given that organizational decisions are activities carried out by people within organizations, two very important sets of assumptions are those concerning the nature of human beings and the organizations that they create. Schrenk cites the view of rational man taken from economic theory as a useful reference point in understanding human behavior. ${ }^{7}$ The as sumptions of the rational or economic man model are that human beings will make rational choices in their self-interest to maximize some utility function, usually based on economic factors. Hence, decisions that do not serve to maximize an economic utility function are irrational.

The OR assumptions about organizations are not often directly stated, but may be inferred from existing writings. Usually, OR writings abou decision-making focus on the individual decision maker or manager. Of ten reference is made to managers or management as if to assume the existence of a classic hierarchical bureaucracy. ${ }^{8}$ All information is assumed to flow upward through control systems to the top manager, who 
personally makes the final decision for the organization. In other words, the operations researchers treat organizations as though they were individual people: as rational, integrated, monolithic decision-makers. No strong distinction is made between managerial and organizational decision-making.

The implicit OR model of organizations appears to be similar to the "rational actor" model utilized by Allison in examining the Cuban missile crisis. Allison outlines the relevant assumptions:

Each assumes that what must be explained is an action, i.e., behavior that reflects government. Each assumes that the action is chosen as a calculated solution to a strategic problem. For each, explanation consists of showing what goal the government was pursuing when it acted and how the action was a reasonable choice, given the nation's objective."

Many operations researchers assume that organizations are purposive, that they are guided by goals and objectives. "' This purposive bias seems to be an extension of the rational man view of human nature and is central to the OR approach to organizations. Organizations are rational and goaldirected, and it is the role of the OR worker to ensure the continuance of that rationality. When an organization does not consistently work to maximize its stated goals and objectives, it is "sick" and requires an OR "doclor" to return it to health.

The OR literature does not dwell on the environment in which the organization finds itself. Very little is stated about the organizational decision environment, except that it is predictable through probabilistic calculation. "In general, the decision or organization environment is treated as an undifferentiated whole. Little evidence was found of attempts to accoun for the effects of varying environmental contingencies on the organization and the decision process.

Morse extols the virtues of planning and then outlines specifically for librarians the demands of the OR approach:

The manager of an existing library or the planner of a new one mus know in some detail how the user of the library will act, how often he will use a catalogue or other reference material, for example, what books or periodicals he will refer to and how long he will need to use each item. As with any other organization in these rapidly changing times, the librarian should know, as accurately as possible, what now is going on and should be able to predict what probably 
will be going on in the future. . . . Administrative decisions, both major and minor, regarding all aspects of library planning and operation, can be wisely reached only in the light of knowledge of present library use and by the careful estimates of future use." ${ }_{12}$

In other words, Morse assumes that proper library decision-making must combine planning, systematic data collection and analysis, modeling of current system behavior, and prediction of future system behavior.

The OR approach assumes that proper decision-making is formal, systematic, and replete with relevant information. Schrenk reviews much of the decision theory literature as relates to $O R$ and outlines an ideal decision process. The process is composed of three phases: the problem recognition phase, which is concerned with the identification of a problem requiring a decision; the problem diagnosis phase that focuses on the probable situation which is producing the problem; and the action selection phase that centers on choosing a course of action. ${ }^{13}$

As mentioned earlier, operations researchers use techniques from engineering and the physical sciences. Thus, it is not surprising that OR workers assume that human decision-making can be improved with the aid of machines, largely through the use of computers. ${ }^{14}$ The presumption is that intendedly rational people can be made more logical and accurate through the use of sophisticated data processing equipment.

In summary, selected OR writings make the following assumptions related to organizational decision-making:

1. The rational man model outlines the essentials of human behavior;

2. Organizations make decisions as individual rational actors;

3. Organizations are purposive and goal-directed;

4. The organizational environment is undifferentiated and predictable through probabilistic calculation;

5. Planning and gathering data are important organizational functions;

6. Modeling of current system behavior and prediction of future behavior are necessary tasks;

7. Decision-making should be a structured, formal, systematic, and goal-directed process;

8. The decision-making capacity of rational human beings can be extended by computers. 


\section{A CONTINGENCY FRAMEWORK}

Richard L. Daft establishes the following definitions:

Organizational decision-making is formally defined as the process of identifying and solving problems. The process contains two major stages. The problem identification stage is where information about environmental and organizational conditions is monitored to determine if performance is satisfactory and to diagnose the cause of shortcomings. The problem solution stage is where alternative courses of action are considered and one alternative is selected and implemented. ${ }^{15}$

Daft then introduces a simple model that helps to assess how two crucial organizational dimensions affect the decision environment. The first dimension, goal uncertainty, concerns the degree of agreement among managers about which organizational goals to pursue. Technical uncertainty, the second dimension, refers to knowledge of cause-and-effect relationships and agreement about how to attain organizational goals. These concepts, when combined with Daft's two phases of organizational decision-making, can be expressed graphically in a two-by-two matrix. ${ }^{16}$ See Figure 1.

Daft then outlines a contingency decision framework. He argues that each cell of the matrix represents an organizational context that is appropriate for a particular model of organizational decision-making. He matches the following models to particular cells: the systems analysis model ${ }^{17}$ to Cell 1; the Carnegie mode ${ }^{18}$ to Cell 2 ; the incremental decision model ${ }^{19}$ to Cell 3; and the garbage can model ${ }^{20}$ to Cell 4.

It is beyond the scope of this paper to detail the components of each model of organizational decision-making. However, a consideration of Daft's description of the systems analysis model is useful:

The systems analysis approach to organization-level decision-making is the analog to the rational approach by individual mangers. Systems analysis came into being during World War II. Mathematical and statistical techniques were applied to urgent, large-scale military problems that were beyond the ability of individual decisionmakers.

Mathematicians, physicists, and operations researchers used systems analysis to develop artillery trajectories, anti-submarine strategies, and bombing strategies such as salvoing. ${ }^{21}$ 


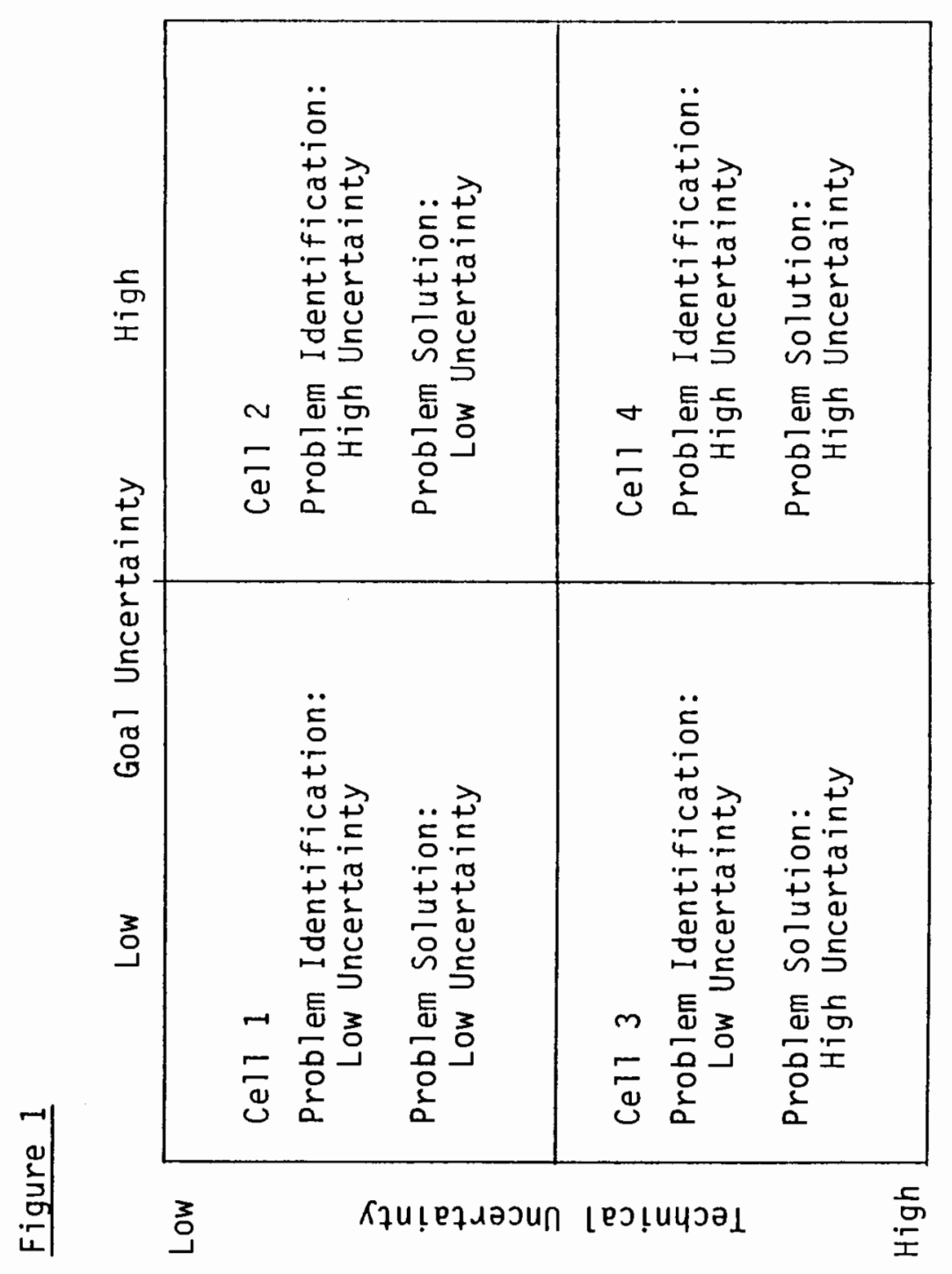


Obviously the OR approach to academic library problems, with its emphasis on rationality and natural science and mathematical techniques, is similar to the systems analysis model. Hence, in Daft's framework, the OR approach would be most applicable to organizational activities for which there is substantial agreement on goals and the best method to achieve those goals. Daft's contention apparently is sensible enough; systems analysis or operations research would be most applicable to a structured task such as auto production in a manufacturing plant where goals and means are shared and understood.

The major question at hand, however, is whether the OR approach is being applied appropriately to organizational decision-making in academic libraries. At first blush, the answer to the question might appear to be positive. Libraries seem to some people to be highly structured, predictable places. Books and periodicals are selected, acquired, processed, and made accessible to patrons in an orderly fashion. Rules dominate the operation of the various services provided by the library. Indeed, the technology of acquiring information in manageable packages and making them available to people in libraries dates back many centuries. Computer and telecommunication technologies have been introduced into academic libraries, but one could make the case that these technologies tend to be used largely as a way of performing old tasks with new tools.

The perception of modern academic libraries as complex, dynamic organizations, however, suggests another view of decision-making in academic libraries. The typical academic library organization is not undifferentiated; it is made up of a number of different people with varying opinions who ordinarily do not think alike nor make decisions in the same fashion. Also, there are parts of the organization that face an uncertain future, while there are other organizational components that confront no such challenge. Similarly, some tasks carried out in academic libraries are completed with little goal or technical uncertainty, while others are beset with many uncertainties.

A major flaw in the writings of the operations researchers interested in libraries is their lack of attention to and oversimplification of the context, both organizational and environmental, of organizational decision-making in academic libraries. Academic library organizations are not all the same, nor does any academic library remain the same organizationally over time. And various parts of the academic library interact in differing ways with the physical, social, political, and economic environment beyond the organization. For example, the cataloger in an academic library faces a much different environment than does the reference librarian in his or her daily meetings with the public. 
Operations researchers interested in academic libraries have paid inadequate attention to the decision environment outside the organization. This inattention greatly narrows the applicability of OR to academic library problems. Based on the OR assumptions outlined earlier and Daft's contingency organizational decision-making framework, the OR approach can be effective only when applied to a routine, highly structured task that takes place in a stable, predictable environment.

There likely are stable areas within academic library organizations in which highly structured tasks amenable to the skills of operations researchers are carried out. However, many other organizational decisions and problems do not fit such neat and tidy criteria. More current research, ${ }^{22}$ as well as informed common sense, suggest that the surrounding environment is much more turbulent than stable. Declining fiscal suppor for academic libraries and rapidly advancing information technologies are just two examples of environmental forces that have had a dramatic effect on academic library decision-making. Any model or approach that purports to help academic library administrators solve problems must deal adequately with environmental forces that impinge on the organizational decision-making process.

Another conceptual problem with applying OR methods to academic library settings is the insistence that libraries are and should be purposive organizations designed to achieve clear goals. To be effective, operation researchers must depend on clearly-stated, unambiguous library goals. Certainly, universities and colleges have oft-stated goals, such as educating youth and conducting research. Academic libraries, too, frequently have articulated goals, such as the goal of serving the information needs of faculty and students. However, these goals are often so general that they are not very useful in guiding day-to-day operational decisions.

Academic library goals tend to be general and platitudinous because the library attempts to serve a broad array of patrons, each with differen needs and preferences. Academic libraries are often focal points for the preferences of influential groups to be played out. Even a cursory examination of possible academic library goals raises difficult questions. Whom does the academic library really serve? The faculty who are the teachers and researchers and permanent residents? The students who are the raison d'être of the university and the largest segment of the campus population? The parents and alumni who pay much of the way for the students? The university administrators possessed of the responsibility for guiding the university? The legislators (in public institutions) who provide continued funding? And what type of services should be provided? Large collections 
of single books and journals to provide maximum subject coverage? Or multiple copies of heavily-used books to improve accessibility at the expense of coverage in purchasing a greater number of individual titles? Should funds be allocated to computer systems to provide increased access to existing books and journals, or should equivalent amounts be spent on badly-needed books? In an academic library where there are patrons with diverse needs and interests, complex issues, and limited resources, the potential for disagreement and uncertainty over appropriate goals is great.

\section{CONCLUSION}

This paper began by examining and discussing the assumptions made by selected operations researchers concerning organizational decisionmaking in academic libraries. Then the operations researchers' assumptions were compared to Richard L. Daft's contingency framework of organizational decision-making ${ }^{23}$ to determine the appropriateness of applying OR assumptions and methods to organizational decision-making in the academic library setting.

A review of the operations researchers' assumptions and Daft's framework suggests that the OR approach may be appropriately applied only to the relatively narrow category of problems or decisions in academic libraries that match the OR assumptions: the goals of the organization mus be clear, specific, and generally accepted; the organization and the environment must be predictable; and the methods of achieving the goals must be clearly understood and widely accepted. Some academic library situations seem to be consistent with the OR assumptions, such as the maintenance of circulation records. Nearly every academic library strives to keep accurate circulation records and is expected to do so. And the methods of keeping records, either automated or manual, generally are understood and accepted.

However, there are many other important academic library problems and decisions that are not well adapted to the operations researchers' craft. When the goals of the library are not well defined or are not widely accepted, operations research methods break down. The conceptual underpinnings, the assumptions upon which the research techniques are based, do not equip operations researchers to confront and resolve problems outside their intellectual ken. And the tendency of academic libraries to have vague, uncertain goals has already been noted. Thus, many of the challenging, long-term problems associated with academic libraries, some might say the most important problems that academic libraries face, may 
not be solvable by OR methods. In the words of Richard De Gennaro, “... a library operates in a political environment and nearly all the really important decisions that are made at the highest levels have an overriding political component. They are rarely the product of cost-benefit analysis or operations research where the various factors are weighed and compared and the 'best' or most cost-effective course is chosen." ${ }^{24}$

Daft's contingency organizational decision-making framework ${ }^{25}$ identifies other decision models that may be more effective under varying organizational contexts. Daft's framework is not presented here as an example of a comprehensive model that describes all organizational decision-making in academic libraries. It is simplistic, accounts for only two organizational variables, and is supported by inadequate research data. However, it does provide a useful starting point for analyzing how operations research may be appropriately applied in academic libraries.

Daft's framework reminds that OR is a serviceable problem solving tool, but a specialized one that is best adapted to problems that exist under conditions of relative organizational stability and certainty. Librarians and library administrators should not allow the scientific aura of operations research to cause them to forget that many sticky academic library problems cannot be easily resolved by OR methods. De Gennaro highlights a potential danger associated with OR and other new management systems:

In the hands of amateurs - and this is most of us - the quantitative systems frequently produce misleading and wrong solutions, while the psychological or behavioral systems can lead to the manipulation and misuse of people. The real danger with both kinds of management systems is that they offer mechanistic formulas for dealing with complex realities and keep us from thinking about and solving our management problems in practical, realistic, and common sense ways. $^{2 h}$

\section{NOTES}

1. Martha Boaz, ed., Current Concepts in Library Management (Littleton, CO: Libraries Unlimited, 1979), p. 249.

2. Boaz, Current Concepts, p. 249.
3. C. R. McClure and A. R. Samuels, eds., Strategies for Library Adminis. tration: Concepts and Approaches (Littleton, CO: Libraries Unlimited, 1982), p. 6.

4. G. A. Mackenzie and M. K. Buckland, "Operational Research," in Reader in Operations Research for Libraries, edited by P. Brophy, M. K. Buck- 
land, and A. Hindle (Englewood, CO: Information Handling Services, Library and Education Division, 1976), p. 349.

5. P. M. Morse, "Library Effectiveness: An Introduction to the Systems Approach," in Reader in Operations Research for Libraries, edited by P. Brophy, M. K. Buckland, and A. Hindle (Englewood, CO: Information Handling Services, Library and Education Division, 1976), p. 36.

6. Mackenzie and Buckland, "Operational Research," p. 350.

7. L. P. Schrenk, "Aiding the Decision-maker: A Decision Process Model," in Reader in Operations Research for Libraries, edited by P. Brophy, M. K. Buckland, and A. Hindle (Englewood, CO: Information Handling Services, Library and Education Division, 1976), p. 123.

8. R. M. Adelson and J. M. Norman, "Operations Research and Decisionmaking," in Reader in Operations Research for Libraries, edited by P. Brophy, M. K. Buckland, and A. Hindle (Englewood, CO: Information Handling Services, Library and Education Division, 1976); Schrenk, "Aiding the Decisionmaker.")

9. Graham T. Allison, Essence of Decision: Explaining the Cuban Missile Crisis (Boston: Little, Brown, 1971), p. 13.

10. Schrenk, "Aiding the Decision-maker;" Adelson and Norman, "Operations Research."

11. Adelson and Norman, "Operations Research."

12. Morse, "Library Effectiveness," p. 34-35.

13. Schrenk, "Aiding the Decision-maker," p. 123-127.

14. Schrenk, "Aiding the Decision-maker."

15. Richard L. Daft, Organization Theory and Design, 2nd ed. (St Paul, MN: West Publishing, 1986), p. 347.

16. Daft, Organization Theory, ch. 9.

17. H. J. Leavitt, W. R. Dill and H. B. Eyring, The Organizational World (New York: Harcourt Brace Jovanovich, 1973).

18. James G. March and Herbert A. Simon, Organizations (New York: John Wiley, 1958).

19. H. Mintzberg, D. Raisinghani and A. Theoret, "The Structure of 'Unstructured' Decision Processes," Administrative Science Quarterly 21, no. 2 (June 1976): 246-275.

20. Michael D. Cohen and James G. March, Leadership and Ambiguity: The American College President, 2nd ed. (Boston: Harvard Business School Press, 1986).

21. Daft, Organization Theory, p. 354.

22. Daft, Organization Theory; March and Simon, Organizations; Mintzberg et al., "The Structure of 'Unstructured' Decision Processes;" Cohen and March, Leadership and Ambiguity.

23. Daft, Organization Theory, ch. 9.

24. Richard De Gennaro, "Library Administration and New Management Systems," Library Journal 103, no. 22 (December 15, 1978):2480.

25. Daft, Organization Theory, ch. 9.

26. De Gennaro, “Library Administration," p. 2482 